\title{
Correspondence
}

Editor: Ian Pullen

Contents: Tardive dyskinesia and lithium/The opiate prescribing debate/The evaluation of mental health care systems/Reliability of GHQ factor structures/ Behaviour disorders in mentally handicapped adults/ Violence in hospital/Asian patients and the HAD scale/Jarman indices and 'new chronic' in-patients/ Post-traumatic stress disorder.

\section{Tardive dyskinesia and lithium}

SIR: Dinan \& Kohen (Journal, July 1989, 155, 55-57) quote Kane et al (1980) as suggesting "that patients with affective illness are at greater risk of developing tardive dyskinesia than are patients with schizophrenia". Since then Wegner et al (1985) have compared schizophrenics with tardive dyskinesia (TD) and those without TD and found that the TD cases had a family history loading for affective disorders in first-degree relatives.

Drs Dinan \& Kohen used DSM-III criteria in their study. The use of various criteria in different studies and the difficulties associated with reaching a consensus definition in the problematic area of 'overlap' (schizoaffective) between schizophrenia and affective disorders (Brockington \& Leff, 1979), together with Drs Dinan \& Kohen's finding of an excess of hospital admissions in their patients, suggest the probability of complex lesions of brain tissue which given time and severity will lead to TD. However, the simplistic belief that neuroleptics or lithium are sufficient causes of TD persists among clinical psychiatrists. This has both theoretical and medico-legal importance.

\section{Child and Family Centre \\ Castleknock \\ Dublin}

JANE FALVEY

\section{References}

Brockington, I. F. \& LeF, J. P. (1979) Schizoaffective psychosis: definitions and incidence. Psychological Medicine, 9, 91-99.

Kane, J., Struve., F. A. \& Wennold, P. (1980) Strategy for the study of patients at high risk for tardive dyskinesia. American Journal of Psychiatry, 137, 1265-1267.

Wegner, J. T., Catalano, F., Gibralter, J., et al (1985) Schizophrenics with tardive dyskinesia: neuropsychological deficit and family psychopathology. Archives of General Psychiatry, 42, 860-865.
SIR: Dinan \& Kohen (Journal, July 1989, 155, 55-57) present evidence suggesting that the duration of lithium therapy may be a risk factor for tardive dyskinesia.

It would be interesting to know whether their patients were maintained on lithium alone, or whether neuroleptics were administered concurrently. If the tardive dyskinetic effect of the lithium treatment was observed in patients receiving no concurrent neuroleptics, then these authors' doubts about the recommendation (Gardos \& Casey, 1984) to maintain bipolar patients on lithium rather than on neuroleptics are indeed well founded. Otherwise, the report has no bearing on that recommendation, since an interaction between lithium and neuroleptics can explain their observation.

The addition of lithium to haloperidol dosing regimen increases the levels of haloperidol in the red blood cells and the plasma of humans (Nemes et al, 1986) as well as in the brain and plasma of guinea pigs (Nemes et al, 1987). These effects of lithium may underlie the reported relationship between the duration of lithium treatment and risk for tardive dyskinesia.

Nathan S. Kline Institute,

JAN Volavka Orangeburg, NY 10962

USA

\section{References}

Gardos, G. \& Casey, D. E. (eds) (1984) Tardive Dyskinesia and Affective Disorders. Washington, DC: American Psychiatric Association.

Nemes, Z. C., Volavka, J., CoOper, T. B., et al (1986) Lithium and haloperidol. Biological Psychiatry, 21, 568-569.

-, -, LAJTHA, A., et al (1987) Concurrent lithium administration results in higher haloperidol levels in brain and plasma of guinea pigs. Psychiatry Research, 20, 313-316.

SIR: Dinan \& Kohen (Journal, July 1989, 155, 55-57) reported a study on tardive dyskinesia in bipolar affective disorder, and suggested that lithium exposure is one variable leading to TD. The observation was made after matching the patients with and without TD in terms of length of illness and duration 